Marquette University

e-Publications@Marquette

Biological Sciences Faculty Research and

Publications

Biological Sciences, Department of

2012

\title{
Structure of Mandelate Racemase with Bound Intermediate Analogues Benzohydroxamate and Cupferron
}

\author{
Adam D. Lietzan \\ Marquette University, adam.lietzan@marquette.edu \\ Mitesh Nagar \\ Dalhousie University \\ Elisa Pellmann \\ Marquette University, elise.pellmann@marquette.edu \\ Jennifer R. Bourque \\ Dalhousie University \\ Stephen L. Bearne \\ Dalhousie University
}

See next page for additional authors

Follow this and additional works at: https://epublications.marquette.edu/bio_fac

Part of the Biology Commons

\section{Recommended Citation}

Lietzan, Adam D.; Nagar, Mitesh; Pellmann, Elisa; Bourque, Jennifer R.; Bearne, Stephen L.; and Maurice, Martin St., "Structure of Mandelate Racemase with Bound Intermediate Analogues Benzohydroxamate and Cupferron" (2012). Biological Sciences Faculty Research and Publications. 107.

https://epublications.marquette.edu/bio_fac/107 
Authors

Adam D. Lietzan, Mitesh Nagar, Elisa Pellmann, Jennifer R. Bourque, Stephen L. Bearne, and Martin St. Maurice

This article is available at e-Publications@Marquette: https://epublications.marquette.edu/bio_fac/107 
Marquette University

e-Publications@Marquette

\title{
Biology Faculty Research and Publications/College of Arts and Sciences
}

This paper is NOT THE PUBLISHED VERSION; but the author's final, peer-reviewed manuscript. The published version may be accessed by following the link in th citation below.

Biochemistry, Vol. 51, No. 6 (2012): 1160-1170. DOI. This article is (C) American Chemical Society and permission has been granted for this version to appear in e-Publications@Marquette. American Chemical Society does not grant permission for this article to be further copied/distributed or hosted elsewhere without the express permission from American Chemical Society.

\section{Structure of Mandelate Racemase with Bound Intermediate Analogues Benzohydroxamate and Cupferron}

\author{
Adam D. Lietzan \\ Department of Biological Sciences, Marquette University, Milwaukee, Wisconsin \\ Mitesh Nagar \\ Department of Biochemistry and Molecular Biology, Dalhousie University, Halifax, NS \\ Elise A. Pellmann \\ Department of Biological Sciences, Marquette University, Milwaukee, Wisconsin \\ Jennifer R. Bourque \\ Department of Biochemistry and Molecular Biology, Dalhousie University, Halifax, NS \\ Stephen L. Bearne \\ Department of Biochemistry and Molecular Biology, Dalhousie University, Halifax, NS \\ Martin St. Maurice \\ Department of Biological Sciences, Marquette University, Milwaukee, Wisconsin
}




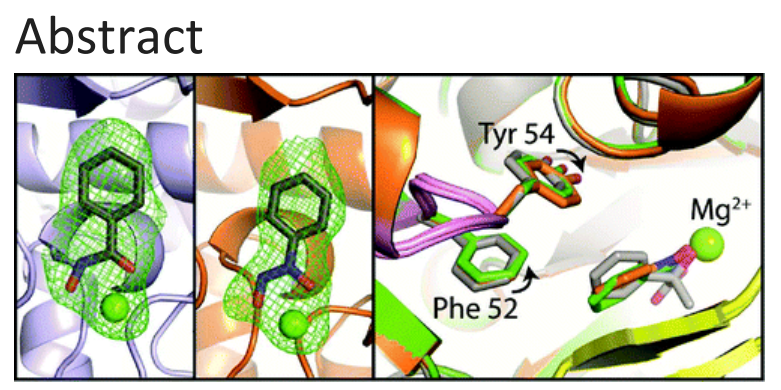

Mandelate racemase (MR, EC 5.1.2.2) from Pseudomonas putida catalyzes the $\mathrm{Mg}^{2+}$-dependent interconversion of the enantiomers of mandelate, stabilizing the altered substrate in the transition state by 26 $\mathrm{kcal} / \mathrm{mol}$ relative to the substrate in the ground state. To understand the origins of this binding discrimination, we determined the X-ray crystal structures of wild-type MR complexed with two analogues of the putative acicarboxylate intermediate, benzohydroxamate and Cupferron, to 2.2-Å resolution. Benzohydroxamate is shown to be a reasonable mimic of the transition state and/or intermediate because its binding affinity for $21 \mathrm{MR}$ variants correlates well with changes in the free energy of transition state stabilization afforded by these variants. Both benzohydroxamate and Cupferron chelate the active site divalent metal ion and are bound in a conformation with the phenyl ring coplanar with the hydroxamate and diazeniumdiolate moieties, respectively. Structural overlays of MR complexed with benzohydroxamate, Cupferron, and the ground state analogue $(S)$ atrolactate reveal that the para carbon of the substrate phenyl ring moves by $0.8-1.2 \AA$ between the ground state and intermediate state, consistent with the proposal that the phenyl ring moves during MR catalysis while the polar groups remain relatively fixed. Although the overall protein structure of MR with bound intermediate analogues is very similar to that of MR with bound $(S)$-atrolactate, the intermediate- $\mathrm{Mg}^{2+}$ distance becomes shorter, suggesting a tighter complex with the catalytic $\mathrm{Mg}^{2+}$. In addition, Tyr 54 moves closer to the phenyl ring of the bound intermediate analogues, contributing to an overall constriction of the active site cavity. However, site-directed mutagenesis experiments revealed that the role of Tyr 54 in MR catalysis is relatively minor, suggesting that alterations in enzyme structure that contribute to discrimination between the altered substrate in the transition state and the ground state by this proficient enzyme are extremely subtle.

\section{FUNDING STATEMENT}

This work was supported by National Institutes of Health Grant GM070455 (M.St.M.), National Science Foundation MRI-R2 grant DBI-0959442 (M.St.M.) and a Discovery Grant from the Natural Sciences and Engineering Research Council (NSERC) of Canada (S.L.B.). A.D.L. is supported by a GAANN award (Graduate Assistance in Areas of National Need) from the U.S. Department of Education. Use of the Advanced Photon Source was supported by U.S. Department of Energy, Office of Science, Office of Basic Energy Sciences, under Contract No. DE-AC02-06CH11357. Use of the LS-CAT Sector 21 was supported by the Michigan Economic Development Corporation and the Michigan Technology Tri-Corridor for the support of this research program (Grant 085P1000817).

Mandelate racemase (MR, EC 5.1.2.2) from Pseudomonas putida catalyzes the $\mathrm{Mg}^{2+}$-dependent 1,1proton transfer that interconverts the enantiomers of mandelate via a two-base mechanism with His 297 and Lys 166 abstracting the $\alpha$-proton from $(R)$-mandelate and $(S)$-mandelate, respectively, as shown in Figure 1. (1) MR is very proficient at discriminating between the substrate in the ground state and the altered substrate in the transition state (TS), binding the latter species with an association constant equal to $5 \times 10^{18} \mathrm{M}^{-}$ ${ }^{1}$ and stabilizing the TS of the reaction by $26 \mathrm{kcal} / \mathrm{mol} .(2,3)$ Consequently, the enzyme has been studied as a paradigm for understanding enzyme-catalyzed abstraction of protons from carbon acids.(1, 4-7) Enzymes such as MR, which are extremely proficient at stabilizing the TSs and intermediates formed during catalysis, are often strongly inhibited by analogues of either the altered substrate in the TS or unstable intermediates that resemble the TS.(8-12)Our interest in understanding how binding determinants within the active site of MR stabilize the TS for $\alpha$-proton abstraction led us to survey a series of reactive intermediate analogues as potential TS or 
intermediate analogue inhibitors,(13-16) leading to the identification of $\alpha$-hydroxybenzylphosphonate $\left(K_{\mathrm{i}}=4.7\right.$ $\mu \mathrm{M}(15))$, benzohydroxamate $(\mathrm{BzH})\left(K_{\mathrm{i}}=9.3 \mu \mathrm{M}(15)\right), N$-hydroxyformanilide $\left(K_{\mathrm{i}}=2.8 \mu \mathrm{M}(13)\right)$, and Cupferron (CfN) $\left(K_{\mathrm{i}}=2.7 \mu \mathrm{M}(13)\right)$ as potent reversible competitive inhibitors of MR. As shown in Figure $\underline{1}$, both BzH and CfN may be regarded as analogues of the aci-carboxylate intermediate.

\section{Figure 1}

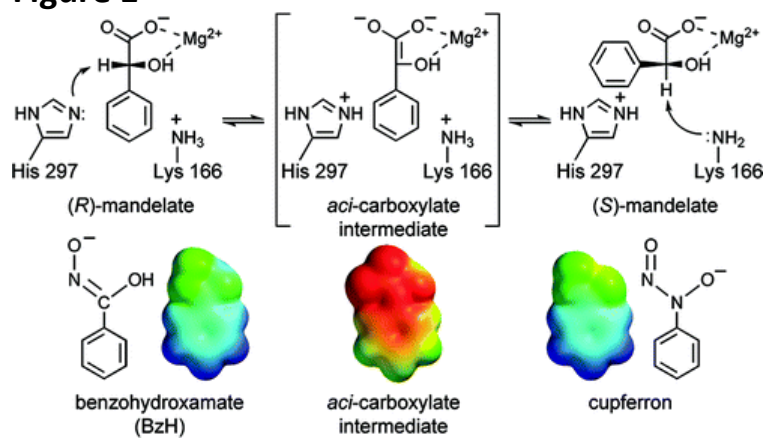

Figure 1. Two-base mechanism for MR-catalyzed racemization of $(R)$ - and $(S)$-mandelate. The molecular electrostatic potential surface (EPS) at the van der Waals radii for the conjugate base of Z-BzH (Odeprotonated(34)), the putative aci-carboxylate intermediate, and the conjugate base of Z-Cupferron(51) are also shown. EPSs have an electron density isosurface displayed at a density of $0.002 \mathrm{e} / \mathrm{a}_{0}{ }^{3}$ that encompasses approximately $95 \%$ of the van der Waals radii.(52) The energy difference from the red (negative potentials) to blue (more electropositive potentials) regions of the EPSs is $150 \mathrm{kcal} / \mathrm{mol}$, with the more electropositive potential fixed at an upper limit of $-50 \mathrm{kcal} / \mathrm{mol}$ for all molecules. Geometry optimizations and ESPs were calculated using the density functional B3LYP/6-311+G** method with Spartan'04 Windows version 1.0.1 (Wavefunction, Inc., Irvine, CA).

Herein, we report a critical analysis of TS mimicry by BzH along with the first structures of MR complexed with the intermediate analogues $\mathrm{BzH}$ and $\mathrm{CfN}$. The primary determinant of high-affinity binding in $\mathrm{MR}$ originates from the coordination of $\mathrm{Mg}^{2+}$ in the active site. The hydrophobic pocket surrounding the aromatic ring constricts around the intermediate analogues, consistent with the contribution of this region to TS stabilization. In general, however, there appear to be few specific enhanced contacts with analogues of the acicarboxylate intermediate.

\section{Materials and Methods}

\section{General}

$(R)$ - and $(S)$-Mandelic acid, benzohydroxamate, and all other reagents, unless mentioned otherwise, were purchased from Sigma-Aldrich Canada Ltd. (Oakville, ON). Cupferron ( $\mathrm{NH}_{4}{ }^{+} \mathrm{salt}$ ) was purchased from Fisher Scientific (Ottawa, ON). Circular dichroism (CD) assays and spectral measurements were conducted using a JASCO J-810 spectropolarimeter. DNA oligonucleotide primers were obtained from Integrated DNA Technologies (Coralville, IA, USA) and restriction endonucleases were purchased from New England Biolabs (Ipswich, MA, USA).

\section{Enzyme Purification}

For X-ray crystallography studies, recombinant MR from $P$. putida was overproduced in and purified from Escherichia coli BL21(DE3) cells transformed with the $\mathrm{pET}-52 \mathrm{~b}(+)-W T M R$ plasmid, a $\mathrm{pET}-52 \mathrm{~b}(+)$ plasmid (Novagen, Madison, WI) containing the MR open reading frame (ORF).(17) This construct encodes the MR gene product (MASWSHPQFEKGALEVLFQGPGYHM $1 . . . M R$ ) with an N-terminal Strepll tag (underlined; $\mathrm{M}_{1}$ represents the first amino acid of wild-type MR). The enzyme was purified by affinity chromatography using Strep-Tactin Superflow resin (IBA GmbH, Göttingen, Germany) as described previously.(17) Upon elution from the column, the enzyme was dialyzed against storage buffer [HEPES buffer (100 mM, pH 7.5) containing $\mathrm{MgCl}_{2}(3.3 \mathrm{mM})$, $\mathrm{NaCl}(200 \mathrm{mM})$, and glycerol $(10 \%, \mathrm{v} / \mathrm{v})]$ and stored at $-20^{\circ} \mathrm{C}$. Four or five enzyme preparations were then 
pooled, dialyzed against HEPES buffer (50 mM, pH 7.5) containing $\mathrm{MgCl}_{2}(3.3 \mathrm{mM})$ and $\mathrm{NaCl}(50 \mathrm{mM})$, and concentrated to $\sim 10 \mathrm{mg} / \mathrm{mL}$ using an Amicon Ultracel-10K centrifugal filter unit (Fisher Scientific). The tag was not removed from the enzyme, and the enzyme preparation was immediately frozen as $50 \mu \mathrm{L}$ aliquots in thinwalled, $250 \mu \mathrm{L}$ polypropylene microcentrifuge tubes in liquid nitrogen and stored at $-80{ }^{\circ} \mathrm{C}$.

\section{Site-Directed Mutagenesis}

With the exception of the Y54F and Y54L variants, mutant MRs bearing an N-terminal hexahistidine tag were prepared and purified as described previously.(15, 18-20) For the Y54F and Y54L MRs, the pET-52b(+)WTMR plasmid was used as the template for polymerase chain reaction-based site-directed mutagenesis using the QuikChange Site-Directed Mutagenesis Kit (Stratagene, La Jolla, CA) and following the protocols described by the manufacturer. The forward $(F)$ and reverse $(R)$ synthetic deoxyoligonucleotide primers used to incorporate the desired mutation into the ORFs encoding the Y54F and Y54L MRs are listed in Table S1 of the Supporting Information. After site-directed mutagenesis, mutant plasmids were used to transform competent $E$. coli $\mathrm{DH} 5 \alpha$ cells for plasmid maintenance. Each mutant ORF was sequenced using commercial automated DNA sequencing (Robarts Research Institute, London, ON) to ensure that no other alterations in the nucleotide sequence had been introduced. E. coli BL21(DE3) cells were used as the host for target gene expression, and the overproduced Strepll-tagged mutant MRs were purified as described previously.(17)

\section{Enzyme Assays}

MR activity was assayed using a CD-based assay by following the change in ellipticity of mandelate at $262 \mathrm{~nm}$ with a $1 \mathrm{~cm}$ light path (unless otherwise indicated) as described by Sharp et al.(21) All assays were conducted at $25^{\circ} \mathrm{C}$ in $\mathrm{Na}^{+}$-HEPES buffer $\left(0.1 \mathrm{M}\right.$, pH 7.5) containing $\mathrm{MgCl}_{2}$ (3.3 mM, unless mentioned otherwise) and bovine serum albumin (BSA, $0.005 \%$ ). The concentrations of $(R)$ - and $(S)$-mandelate for assays of all mutant MR enzymes ranged between 0.25 and $10.0 \mathrm{mM}$.

Competitive inhibition experiments with $\mathrm{BzH}$ were conducted in $\mathrm{Na}^{+}-\mathrm{HEPES}$ buffer $(0.1 \mathrm{M}, \mathrm{pH} 7.5)$ containing $\mathrm{MgCl}_{2}$ (3.3 mM, unless mentioned otherwise) and $(R)$-mandelate (0.5-20.0 mM). Enzyme concentrations and assay details have been described previously.(15, 18-20)For the inhibition experiments, the following concentrations of the mutant enzyme and $\mathrm{BzH}$ were used: $150 \mathrm{ng} / \mathrm{mL}$ and 20, 40, and $60 \mu \mathrm{M}$, respectively, for the wild-type; $158 \mathrm{ng} / \mathrm{mL}$ and $10,20,30$, and $40 \mu \mathrm{M}$, respectively, for Y54F; $321 \mathrm{ng} / \mathrm{mL}$ and 25 , 50 , and $75 \mu \mathrm{M}$, respectively, for $\mathrm{Y} 54 \mathrm{~L}$ (using a cuvette with a $0.5 \mathrm{~cm}$ light-path); $300 \mathrm{ng} / \mathrm{mL}$ and 200, 400, and $600 \mu \mathrm{M}$, respectively, for $\mathrm{V} 22 \mathrm{~A} ; 150 \mathrm{ng} / \mathrm{mL}$ and 20,40 , and $60 \mu \mathrm{M}$, respectively, for $\mathrm{V} 22 \mathrm{l} ; 300 \mathrm{ng} / \mathrm{mL}$ and 100 , 200 , and $400 \mu \mathrm{M}$, respectively, for V22F; $450 \mathrm{ng} / \mathrm{mL}$ and 100, 200, and $300 \mu \mathrm{M}$, respectively, for T24S; 500 $\mathrm{ng} / \mathrm{mL}$ and 200,400 , and $600 \mu \mathrm{M}$, respectively, for $\mathrm{A} 25 \mathrm{~V} ; 150 \mathrm{ng} / \mathrm{mL}$ and 25,50 , and $75 \mu \mathrm{M}$, respectively, for $\mathrm{V} 26 \mathrm{~A} ; 450 \mathrm{ng} / \mathrm{mL}$ and 200, 400, and $600 \mu \mathrm{M}$, respectively, for V26L; $450 \mathrm{ng} / \mathrm{mL}$ and 300, 500, and $700 \mu \mathrm{M}$, respectively, for V26F; $500 \mathrm{ng} / \mathrm{mL}$ and 50, 100, and $200 \mu \mathrm{M}$, respectively, for V26A/V29L; $150 \mathrm{ng} / \mathrm{mL}$ and 150, 300 , and $600 \mu \mathrm{M}$, respectively, for $\mathrm{V} 29 \mathrm{~A} ; 150 \mathrm{ng} / \mathrm{mL}$ and 20, 40, and $80 \mu \mathrm{M}$, respectively, for V29L; and 450 $\mathrm{ng} / \mathrm{mL}$ and 60,90 , and $120 \mu \mathrm{M}$, respectively, for V29F. Inhibition constants $\left(K_{\mathrm{i}}\right)$ were determined by fitting the initial velocity data to eq 1 using nonlinear regression analysis and KaleidaGraph version 4.02 from Synergy Software (Reading, PA). All kinetic parameters were determined in triplicate, and average values are reported. The reported errors are standard deviations. The concentrations of variant MRs were determined using either the Bio-Rad protein assay (Bio-Rad Laboratories, Mississauga, ON) with BSA standards or from their absorbance at $280 \mathrm{~nm}$ using extinction coefficients of $53400 \mathrm{M}^{-1} \mathrm{~cm}^{-1}$ (wild-type) and $51910 \mathrm{M}^{-1} \mathrm{~cm}^{-1}$ (Y54F and Y54L) that were calculated using the ProtParam tool available on the ExPASy server (http://web.expasy.org/protparam).(22)

$$
v_{i}=\frac{V_{\max }[\mathrm{S}]}{K_{\mathrm{m}}\left(1+[\mathrm{I}] / K_{i}\right)+[\mathrm{S}]}
$$




\section{Protein Crystallization}

Crystals of the $\mathrm{BzH}$ and $\mathrm{CfN}$ complexes with MR were grown by the hanging drop vapor diffusion method against a $500 \mu \mathrm{L}$ reservoir volume. The protein solution and reservoir solution were mixed in a 1:1 ratio to a final volume of $4 \mu \mathrm{L}$. Crystals grew spontaneously at $21^{\circ} \mathrm{C}$ and $\sim 50 \%$ humidity.

\section{$\mathrm{MR}$ with $\mathrm{BzH}$}

For the MR crystals grown in the presence of $\mathrm{BzH}$, the reservoir solution consisted of PEG 1500 (14\%), glycine $(200 \mathrm{mM}), \mathrm{Nal}(50 \mathrm{mM})$, and triethanolamine buffer $(100 \mathrm{mM}, \mathrm{pH} 8.0)$. The protein solution consisted of $6.4 \mathrm{mg} / \mathrm{mL}$ MR purified as described above, $\mathrm{MgCl}_{2}(3.3 \mathrm{mM}), \mathrm{BzH}(2 \mathrm{mM})$, and HEPES buffer ( $\left.50 \mathrm{mM}, \mathrm{pH} 7.5\right)$. The resulting cubelike crystals $(\sim 65 \mu \mathrm{m} \times 65 \mu \mathrm{m} \times 40 \mu \mathrm{m})$ grew to full size within 5-10 days. After 15 days, the crystals were harvested and transferred to a synthetic stabilizing solution consisting of PEG 1500 (24\%), glycine (210 mM), Nal (50 mM), BzH (2 mM), and triethanolamine buffer $(80 \mathrm{mM}, \mathrm{pH} 8.0)$. These stabilized crystals were transferred in four successive steps to a cryoprotectant solution at ratios of $3: 1,1: 1,1: 3$, and 0:4 (synthetic:cryoprotectant), with an equilibration time of 5-10 min between transfers. The cryoprotectant consisted of PEG 1500 (38\%), glycine (210 mM), Nal (50 mM), BzH (3 mM), and triethanolamine buffer ( $80 \mathrm{mM}$, $\mathrm{pH}$ 8.0). The cryoprotected crystals were flash-cooled in a nitrogen gas stream at $100 \mathrm{~K}$.

\section{MR with CfN}

For the MR crystals grown in the presence of CfN, the reservoir solution consisted of PEG 1500 (20\%), glycine $(120 \mathrm{mM}), \mathrm{Nal}(50 \mathrm{mM})$, and Bis-tris propane buffer $(100 \mathrm{mM}, \mathrm{pH} 9.3)$. The protein solution consisted of $6.4 \mathrm{mg} / \mathrm{mL}$ MR purified as described above, $\mathrm{MgCl}_{2}(3.3 \mathrm{mM}), \mathrm{CfN}(2 \mathrm{mM})$, and HEPES buffer ( $\left.50 \mathrm{mM}, \mathrm{pH} 7.5\right)$. The resulting cubelike crystals $(\sim 65 \mu \mathrm{m} \times 65 \mu \mathrm{m} \times 40 \mu \mathrm{m})$ grew to full size within 5-10 days. After 38 days, the crystals were harvested and transferred directly to a cryoprotectant solution consisting of PEG 1500 (44\%), glycine $(150 \mathrm{mM}), \mathrm{CfN}(2 \mathrm{mM})$, and Bis-tris propane buffer $(100 \mathrm{mM}, \mathrm{pH} 9.3)$, with an equilibration time of 5-10 min. The cryoprotected crystals were flash-cooled in a nitrogen gas stream at $100 \mathrm{~K}$.

\section{Data Collection, Structure Determination, and Refinement}

X-ray diffraction data were collected at the Advanced Photon Source (APS) beamline LS-CAT-21-ID-F on a Rayonix MarMosaic 225 CCD detector, with an X-ray wavelength of $0.978 \AA$. Diffraction images were processed using HKL2000.(23) The structures were determined by molecular replacement using the wild-type MR enzyme [Protein Data Bank (PDB) entry $\underline{2 M N R}$ ] as the search model with Phaser.(24) The molecular replacement models were extended by several rounds of manual model building with COOT $(25)$ and refinement with REFMAC(26) using a geometric/X-ray weighting term of 0.2. Noncrystallographic restraints between each monomer were applied for the first round of refinement but were relieved for subsequent rounds. Water molecules were added to the model in COOT with subsequent manual verification. CfN ligand coordinates were generated and optimized for structure refinement using electronic ligand building and optimization workbench (eLBOW).(27) Data collection and processing statistics are summarized in Table $\underline{1}$.

Table 1. Data Collection and Refinement Statistics

\begin{tabular}{|l|l|l|}
\hline & MR-BzHa & MR-CfNa \\
\hline PDB entry & $3 U X K$ & $3 U X L$ \\
\hline space group & 14 & 14 \\
\hline cell dimensions & & \\
\hline$a, b, c(\AA)$ & $148,148,170$ & $148,148,175$ \\
\hline$\alpha, \beta, \gamma($ deg) & $90,90,90$ & $90,90,90$ \\
\hline resolution range (A) & $50.0-2.20(2.24-2.20)$ & $50.0-2.20(2.24-2.20)$ \\
\hline redundancy & $7.6(7.1)$ & $4.2(3.8)$ \\
\hline completeness (\%) & $100(100)$ & $100(100)$ \\
\hline no. of unique reflections & 92311 & 95130 \\
\hline$R_{\text {merge }}(\%)$ & $10.5(25.3)$ & $8.5(31.7)$ \\
\hline average $/ / \sigma$ & $28.0(8.3)$ & $17.5(3.6)$ \\
\hline
\end{tabular}




\begin{tabular}{|c|c|c|}
\hline \multicolumn{3}{|l|}{ Refinement } \\
\hline resolution range (Å) & $50.0-2.20(2.26-2.20)$ & $50.0-2.20(2.26-2.20)$ \\
\hline $\boldsymbol{R}_{\text {cryst }}$ & $0.162(0.171)$ & $0.182(0.205)$ \\
\hline$R_{\text {free }}$ & $0.193(0.204)$ & $0.227(0.249)$ \\
\hline no. of protein atoms & 11529 & 11280 \\
\hline no. of water molecules & 749 & 565 \\
\hline Wilson $B$ value $\left(\AA^{2}\right)$ & 27.7 & 32.8 \\
\hline \multicolumn{3}{|l|}{ average $B$ factor $\left(\AA^{2}\right)$} \\
\hline protein & 17.2 & 24.5 \\
\hline ligands & 40.7 & 37.9 \\
\hline $\mathrm{Mg}^{2+}$ & 12.7 & 15.4 \\
\hline solvent & 21.0 & 25.3 \\
\hline \multicolumn{3}{|l|}{ Ramachandran plot (\%) } \\
\hline most favored & 90.6 & 90.6 \\
\hline additionally allowed & 8.7 & 8.7 \\
\hline generously allowed & 0.3 & 0.3 \\
\hline disallowed & 0.3 & 0.3 \\
\hline \multicolumn{3}{|l|}{ rmsd } \\
\hline bond lengths (Å) & 0.014 & 0.015 \\
\hline bond angles (deg) & 1.355 & 1.641 \\
\hline
\end{tabular}

\section{Results and Discussion}

\section{Transition State Mimicry}

Hydroxamates have been used as structural mimics of aci-carboxylate intermediates in the characterization of several enolase superfamily enzymes.(28-31) $\mathrm{BzH}$ is a structural and electronic mimic of the aci-carboxylate intermediate and is bound by MR with an affinity that is 100 -fold greater than that exhibited for the substrate.(15) The high binding affinity of $\mathrm{BzH}$, however, is not sufficient evidence to classify BzH as a TS analogue. The degree to which an intermediate/TS analogue mimics the structural and electronic character of the true TS can be assessed by comparing the effects of equivalent structural perturbations on the binding affinity of the altered substrate in the TS (via effects on $k_{\mathrm{cat}} / K_{\mathrm{m}}$ ) and on the binding affinity of the putative TS analogue (via effects on $\left.K_{\mathrm{i}}\right) \cdot(32,33)$ On the basis of eq $\underline{2}$

$$
\log \left(\frac{k_{\mathrm{cat}}}{K_{\mathrm{m}}}\right)=\log k_{\mathrm{non}}+\log \left(\frac{1}{K_{\mathrm{tx}}}\right)
$$

where $k_{\text {non }}$ is the first-order rate constant for reaction in the absence of enzyme and $K_{\mathrm{tx}}$ is the virtual dissociation constant for the enzyme-substrate complex in the TS, a correlation between the free energy change accompanying inhibitor binding (from $1 / K_{\mathrm{i}}$ values) and the relative free energies of activation (from $k_{\text {cat }} / K_{m}$ values) for a variety of mutant enzymes catalyzing the same reaction is expected. $(32,33)$ If a TS analogue inhibitor captures a significant portion of the binding free energy expected for the altered substrate in the TS, then the observed binding affinity, $K_{\mathrm{i}}$, should approximate $K_{\mathrm{tx}}$. Table $\underline{2}$ shows the values of $K_{\mathrm{m}}, k_{\text {cat, }}$ and $k_{\text {cat }} / K_{\mathrm{m}}$ for wild-type MR and 20 variants along with the competitive inhibition constants for inhibition of these enzymes by $\mathrm{BzH}$. The linear free energy relationship relating the relative free energies of activation for the wild-type and variant enzymes to the corresponding free energies of $\mathrm{BzH}$ binding is shown in Figure $2 \mathrm{~A}$. While the slope is unity, the correlation is weak $\left(r^{2}=0.74\right)$. However, the linear free energy relationship relating the relative free energies of substrate binding (from $1 / K_{\mathrm{m}}$ values) to free energies of inhibitor binding (Figure $\underline{2} \mathrm{~B}$ ) has 
a slope of only 0.25 and a much weaker correlation $\left(r^{2}=0.14\right)$, showing that BzH does indeed exhibit mimicry of the altered substrate in the TS and is not simply acting as a ground state analogue. A detailed analysis of the linear free energy relationship has not been performed for CfN. However, it is isosteric and isoelectronic with $\mathrm{BzH}$ (Figure 1) and is bound by the enzyme with high affinity.(13) On this basis, and given that it is bound by MR in a manner analogous to that of $\mathrm{BzH}$ (vide infra), CfN may also be regarded as a mimic of the aci-carboxylate intermediate.

Figure 2
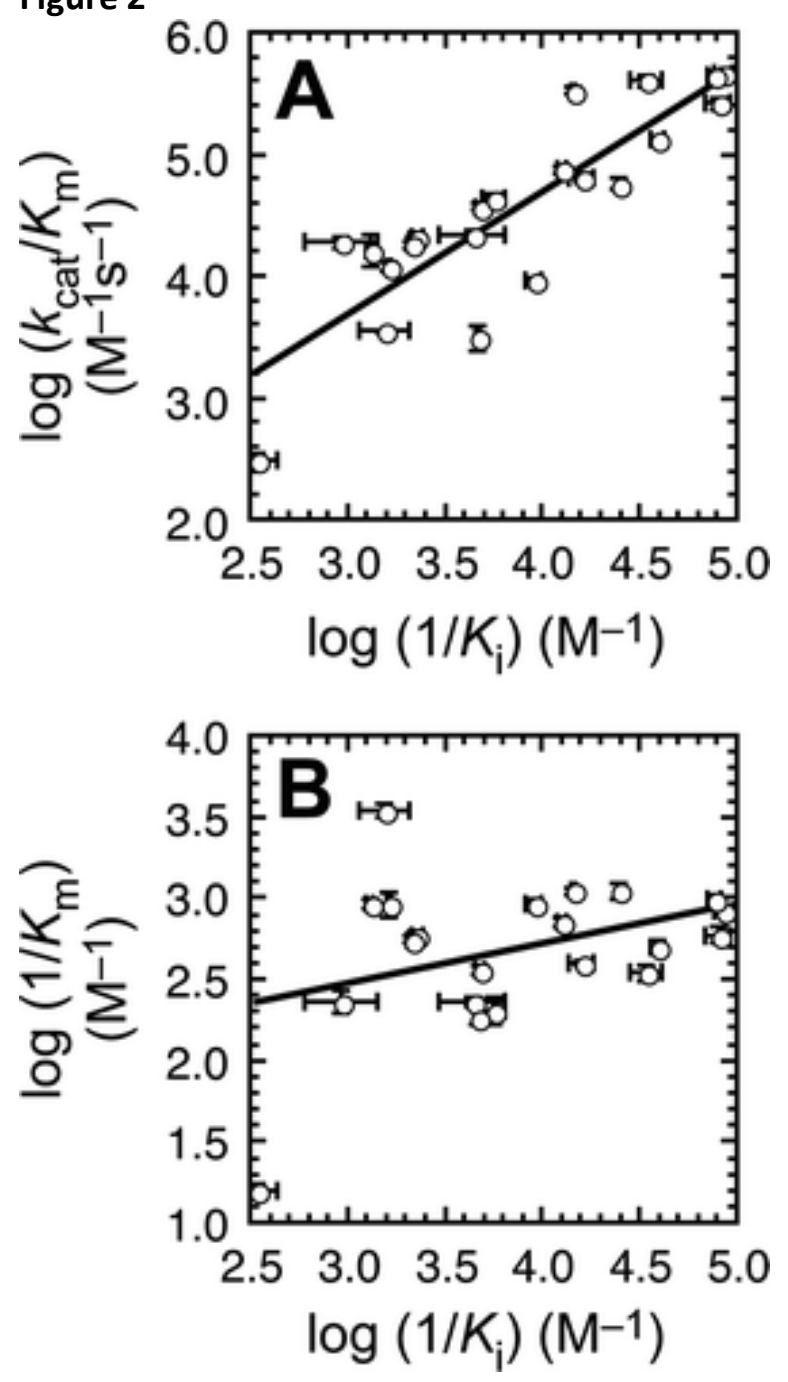

Figure 2. Linear free energy relationships between $K_{\mathrm{i}}$ values for the competitive inhibition of MR variants by benzohydroxamate and the corresponding $k_{\mathrm{cat}} / K_{\mathrm{m}}(\mathrm{A})$ and $K_{\mathrm{m}}(\mathrm{B})$ values for the variants. The curves shown are the linear regression lines with values for the slope, $y$-intercept, and correlation coefficient $\left(r^{2}\right)$ equal to $1.01 \pm$ $0.14,0.65 \pm 0.54$, and 0.7379 , respectively, for panel $A$ and $0.25 \pm 0.14,1.72 \pm 0.56$, and 0.1406 , respectively, for panel $\mathrm{B}$.

Table 2. Kinetic Constants $\left(\boldsymbol{k}_{\mathrm{cat}}, K_{\mathrm{m}}\right.$, and $\left.\boldsymbol{k}_{\mathrm{cat}} / K_{\mathrm{m}}\right)$ and Competitive Inhibition Constants $\left(K_{\mathrm{i}}\right)$ for the Inhibition of MR Variants by Benzohydroxamatea

\begin{tabular}{|l|l|l|l|l|}
\hline & kinetic constants $(R \rightarrow S)$ & & & \\
\hline & $K_{\mathrm{m}}(\mathrm{mM})$ & $k_{\mathrm{cat}}\left(\mathrm{s}^{-1}\right)$ & $k_{\mathrm{cat}} / K_{\mathrm{m}}\left(\mathrm{M}^{-1} \mathrm{~s}^{-1}\right)$ & $K_{\mathrm{i}}(\mu \mathrm{M})$ \\
\hline wild-type $\underline{b}$ & $1.20 \pm 0.04$ & $552 \pm 6$ & $(4.6 \pm \mathbf{0 . 2}) \times 10^{5}$ & $11.7 \pm 1.2$ \\
\hline & $(0.97 \pm 0.09) \underline{c}$ & $(470 \pm 10) \underline{\mathrm{c}}$ & $(\mathbf{4 . 8} \pm \mathbf{0 . 3}) \times 10^{5} \underline{\mathrm{c}}$ & \\
\hline Y54F & $1.02 \pm 0.06$ & $456 \pm 16$ & $(4.5 \pm 0.3) \times 10^{5}$ & $13.0 \pm 1.1$ \\
\hline
\end{tabular}




\begin{tabular}{|c|c|c|c|c|}
\hline & $(0.90 \pm 0.08) \underline{c}$ & $(397 \pm 21) \underline{c}$ & $(4.4 \pm 0.5) \times 10^{5} \underline{c}$ & \\
\hline \multirow[t]{2}{*}{ Y54L } & $2.0 \pm 0.2$ & $253 \pm 4$ & $(1.3 \pm 0.1) \times 10^{5}$ & $25.7 \pm 1.9$ \\
\hline & $(2.3 \pm 0.3) \underline{c}$ & $(301 \pm 9) \underline{c}$ & $(1.3 \pm 0.2) \times 10^{5} \underline{c}$ & \\
\hline V22A $\underline{b}$ & $4.4 \pm 0.7$ & $82 \pm 3$ & $(1.9 \pm 0.2) \times 10^{4}$ & $1080 \pm 460$ \\
\hline V22l $\underline{b} \underline{\text { d }}$ & $2.9 \pm 0.3$ & $(1.15 \pm 0.05) \times 10^{3}$ & $(4.0 \pm 0.4) \times 10^{5}$ & $29.2 \pm 5.2$ \\
\hline $\mathrm{V} 22 \mathrm{~F} \underline{\mathrm{b}}$ & $4.4 \pm 0.3$ & $98 \pm 3$ & $(2.2 \pm 0.2) \times 10^{4}$ & $229.0 \pm 86.6$ \\
\hline T24S $\underline{b}$ & $2.8 \pm 0.2$ & $102 \pm 2$ & $(3.7 \pm 0.2) \times 10^{4}$ & $209.5 \pm 9.9$ \\
\hline $\mathrm{A} 25 \mathrm{~V} \underline{\mathrm{b}}$ & $1.1 \pm 0.2$ & $13 \pm 1$ & $(1.2 \pm 0.1) \times 10^{4}$ & $610.6 \pm 12.2$ \\
\hline V26Ā $\bar{b}$ & $0.91 \pm 0.05$ & $304 \pm 3$ & $(3.3 \pm 0.2) \times 10^{5}$ & $69.3 \pm 2.2$ \\
\hline V26L $\underline{b}$ & $1.7 \pm 0.1$ & $36 \pm 4$ & $(2.1 \pm 0.2) \times 10^{4}$ & $440.4 \pm 26.9$ \\
\hline V26F $\underline{b}$ & $1.8 \pm 0.1$ & $33 \pm 1$ & $(1.8 \pm 0.1) \times 10^{4}$ & $461.6 \pm 31.7$ \\
\hline V26A/V29L므 & $1.4 \pm 0.1$ & $106 \pm 0.4$ & $(7.5 \pm 0.5) \times 10^{4}$ & $79.2 \pm 3.6$ \\
\hline V29Ab & $5 \pm 1$ & $(2.4 \pm 0.2) \times 10^{2}$ & $(4.4 \pm 0.4) \times 10^{4}$ & $178.6 \pm 23.3$ \\
\hline V29Lb̄ & $1.7 \pm 0.2$ & $(3.0 \pm 0.1) \times 10^{2}$ & $(2.6 \pm 0.3) \times 10^{5}$ & $12.5 \pm 1.8$ \\
\hline V29F $\underline{b}$ & $0.9 \pm 0.1$ & $53 \pm 1$ & $(5.7 \pm 0.7) \times 10^{4}$ & $40.1 \pm 0.2$ \\
\hline V29De & $63 \pm 6$ & $19 \pm 2$ & $(3.1 \pm 0.4) \times 10^{2}$ & $2900 \pm 700$ \\
\hline N197Af & $5.40 \pm 0.66$ & $16.9 \pm 3.5$ & $(3.1 \pm 0.7) \times 10^{3}$ & $216 \pm 6$ \\
\hline E317Qe & $1.10 \pm 0.07$ & $0.18 \pm 0.05$ & $(1.6 \pm 0.5) \times 10^{4}$ & $760 \pm 31$ \\
\hline $\mathrm{F} 52 \mathrm{Wg}$ & $2.5 \pm 0.1$ & $159 \pm 17$ & $(6.4 \pm 0.5) \times 10^{4}$ & $63 \pm 10$ \\
\hline Y54Wg'h & $1.1 \pm 0.1$ & $10 \pm 1$ & $(9.3 \pm 0.4) \times 10^{3}$ & $110 \pm 10$ \\
\hline F52W/Y54Wg & $0.29 \pm 0.03$ & $1.0 \pm 0.1$ & $(3.5 \pm 0.1) \times 10^{3}$ & $640 \pm 190$ \\
\hline
\end{tabular}

a Values are means of triplicate trials, and reported errors are standard deviations.

${ }^{\mathrm{b}}$ Kinetic constants $k_{\mathrm{cat}}, K_{\mathrm{m}}$, and $k_{\mathrm{cat}} / K_{\mathrm{m}}$ are from ref $\underline{20}$.

'Kinetic parameters in the $S \rightarrow R$ direction.

${ }^{\mathrm{d}}$ Kinetic parameters determined using $20 \mathrm{mM} \mathrm{Mg}^{2+}$.

eValues of $k_{\text {cat }}, K_{\mathrm{m}}, k_{\mathrm{cat}} / K_{\mathrm{m}}$, and $K_{\mathrm{i}}$ are from ref $\underline{18}$.

fValues of $k_{\text {cat }}, K_{\mathrm{m}}, k_{\text {cat }} / K_{\mathrm{m}}$, and $K_{\mathrm{i}}$ are from ref $\underline{\underline{15}}$.

gValues of $k_{\text {cat }}, K_{\mathrm{m}}, k_{\text {cat }} / K_{\mathrm{m}}$, and $K_{\mathrm{i}}$ are from ref $\underline{19}$.

${ }^{\text {h}}$ Kinetic constants determined using $15 \mathrm{mM} \mathrm{Mg}^{2+}$.

$\mathrm{BzH}$ possesses two sites of deprotonation (i.e., oxygen and nitrogen); therefore, several structures may exist in solution. This is also the case for $\mathrm{CfN}$. In water, $\mathrm{BzH}$ exists primarily in the keto form, and experimental evidence suggests that $\mathrm{BzH}$ undergoes O-deprotonation in water,(34) yielding a species that does not closely resemble the putative aci-carboxylate intermediate. The $\mathrm{pH}$ dependence of $\mathrm{BzH}$ inhibition of $\mathrm{MR}$ is consistent with the deprotonated form of $\mathrm{BzH}$ being preferentially bound by the enzyme.(15) The O-deprotonated enol form of $\mathrm{BzH}$ has never been observed in water; however, this form of $\mathrm{BzH}$ (cis or trans) more closely resembles the structure of the putative aci-carboxylate intermediate and may therefore be preferentially stabilized within the active site of MR.(15)

While $\mathrm{BzH}$ and $\mathrm{CfN}$ embody certain features of the high-energy intermediate, they are not perfect analogues of the TS for several reasons. First, the electrostatic potential surfaces of BzH and CfN do not perfectly mimic the putative intermediate (Figure 1). Second, BzH and CfN lack an oxygen that is present in the acicarboxylate intermediate, which does impose a limitation on our structural analysis. Gerlt and Gassman(6) have suggested that the most effective TS analogue inhibitors for MR will have $\mathrm{p} K_{\mathrm{a}}$ values that match that of the intermediate. According to Gerlt and Gassman, the $\mathrm{p} K_{\mathrm{a}}$ of the neutral intermediate is critical to the formation of a short, strong $\mathrm{H}$-bond between the general acid catalyst Glu 317 and the intermediate, which stabilizes the intermediate and thereby lowers its energy. If, indeed, formation of a short, strong H-bond with Glu 317 dominates the stabilization of the intermediate, then this may limit the extent of mimicry afforded by BzH and $\mathrm{CfN}$. In our structures, the intermediate analogues do not interact with Glu 317 because the hydroxamate and diazeniumdiolate groups of $\mathrm{BzH}$ and $\mathrm{CfN}$, respectively, assume a cis geometry and chelate the $\mathrm{Mg}^{2+}$ within the enzyme's active site (vide infra). Even if BzH and CfN were bound with the trans geometry permitting interaction 
with Glu 317, their respective $\mathrm{p} K_{\mathrm{a}}$ values of $8.8(34,35)$ and $4.2(36-38)$ are several units removed from the $\mathrm{p} K_{\mathrm{a}}$ of Glu 317 (estimated to be $\sim 6$ in $\mathrm{MR}(6,39)$ ). Although the inability of $\mathrm{BzH}$ to interact with Glu 317 may attenuate the degree to which $\mathrm{BzH}$ serves as a perfect mimic of the aci-carboxylate intermediate/TS, the linear free energy relationship and structural features of $\mathrm{BzH}$ indicate that $\mathrm{BzH}$ does respond to changes in TS stabilization afforded by MR variants.

\section{General Description of MR Structure}

MR is composed of three distinct structural domains:(40) an N-terminal capping domain consisting of a three-stranded $\beta$-sheet with an antiparallel four- $\alpha$-helix bundle, a central domain consisting of a $(\beta / \alpha)_{7} \beta$-barrel, and a short $C$-terminal domain composed of external $\beta$-strands. As with all TIM-barrel enzymes, the active site is located at the $\mathrm{C}$-terminal ends of the $\beta$-strands near the mouth of the barrel. The majority of residues involved in ligand binding, metal ion coordination, and catalysis extend from the $\beta$-strands of the barrel.(41-43)Residues located in the $\mathrm{N}$-terminal capping domain form a hydrophobic cavity that contributes to substrate specificity. This cavity may be partitioned into an $R$-specific and $S$-specific pocket (Figure $\underline{3}$ ) where the phenyl group of $(R)$ and $(S)$-mandelate, respectively, is bound upon entering the active site.(19,20) Existing X-ray crystal structures include inorganic sulfate,(40) (S)-mandelate,(41) or the substrate analogue (S)-atrolactate(42-44) bound in the active site, but there is no structural information available regarding the binding orientation of the planar acicarboxylate intermediate in the active site.

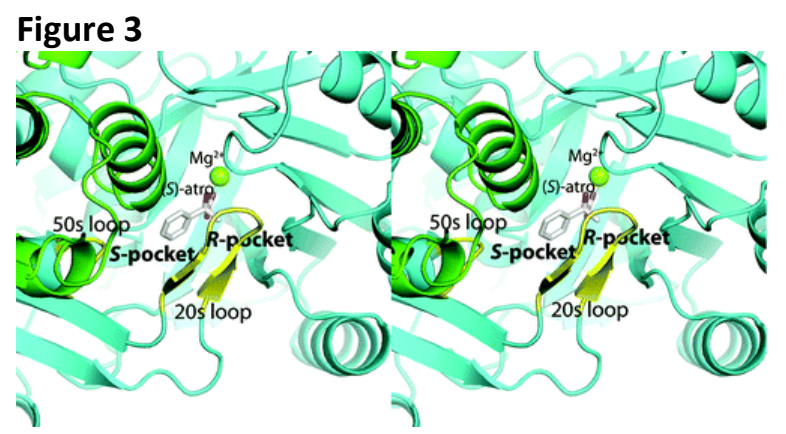

Figure 3. Stereoview of the representative active site architecture of $\mathrm{MR}$ with $\mathrm{Mg}^{2+}$ and $(S)$-atrolactate $[(S)$-atro] bound in the enzyme active site (PDB entry $1 \mathrm{MDR}$ ). The active site has been proposed to include an $R$-specific pocket and an $S$-specific pocket, which bind the phenyl group of $(R)$ - and $(S)$-mandelate, respectively.(19, 46) The $S$-specific pocket is composed of residues from the 50s loop (colored yellow) and residues 90-95 of a neighboring subunit (colored green). The $R$-specific pocket is comprised primarily of residues in the 20s loop (colored yellow). The phenyl ring must translocate between the $R$ - and $S$-specific pockets during catalysis (see Results and Discussion).

The X-ray crystal structures of MR complexed with the intermediate analogues, BzH and CfN, were each determined to 2.2-Å resolution. In both structures, MR is a homo-octamer generated from a tetramer of dimers. Each dimer pair is generated through a tight association between neighboring subunits, with both members of the pair contributing residues to the neighboring active site.(40) Unlike previously reported MR crystal structures, both of the current structures were determined from crystals in space group 14 and included two separate dimers in the asymmetric unit. Each dimer forms an independent octamer through crystallographic symmetry (Figure S1 of the Supporting Information). The two dimers are nearly identical; the only differences between them are two slight twists in the first and second helices of the $(\beta / \alpha)_{7} \beta$-barrel (Figure S2 of the Supporting Information). This small difference between the two octamers is sufficient to render the symmetry noncrystallographic but does not influence the packing of the octamer or the conformation in the individual active sites. Consequently, descriptions of intermediate analogue binding are limited to one representative active site, with all other active sites being identical in their interactions. 


\section{Structures of $\mathrm{BzH}$ and $\mathrm{CfN}$ in the Active Site}

The electron density for the $\mathrm{BzH}$ and $\mathrm{CfN}$ ligands is well-defined over the entire molecule in all four active sites, though the carbon atoms in the aromatic ring of $\mathrm{BzH}$ have higher relative temperature factors than the rest of the molecule (Figure 4 ). The root-mean-square deviations (rmsds) for structural alignments of the chain A $\alpha$-carbon atoms of MR bound to (S)-atrolactate (PDB entry $\underline{1 M D R}$ ) with MR bound to BzH and CfN are 0.32 and $0.38 \AA$, respectively. The rmsds for alignment of the chain $A \alpha$-carbon atoms of the apo MR structure (PDB entry 2MNR) with the structures of MR bound to $\mathrm{BzH}$ and $\mathrm{CfN}$ are 0.32 and $0.36 \AA$, respectively. Hence, there is no crystallographic evidence of large structural changes accompanying the enzyme's transition from the unbound state to the $(S)$-atrolactate-bound ground state to the intermediate-bound state. There are also no gross differences in the conformation of the 20 s or 50 s loops between the ground state-bound and intermediate-bound structures (Figure $\underline{5} B$ ). Indeed, comparison of the structures of MR complexed with the ground state analogue $(S)$-atrolactate with the structures of MR complexed with the intermediate analogues $\mathrm{Bz} H$ and CFN reveals that the positions of only a few amino acid side chains are altered. Relative to its position in the (S)-atrolactate-bound structure, Lys 166, the $S$-specific general base catalyst, moves closer to the $\alpha$-carbon of the planar intermediate analogues (Figure $\underline{5} \mathrm{~A})$. Because MR is a pseudosymmetric enzyme $(45)$ with $k_{\text {cat }}$ values in the $S \rightarrow R$ and $R \rightarrow S$ directions being approximately equal, one would anticipate that both Lys 166 and His 297 would be in nearly equal proximity to the $\alpha$-carbon of the aci-carboxylate intermediate and equally poised to protonate it (Figure 1). The structure of MR with bound $\mathrm{BzH}$ is in agreement with this expectation, and this is the first structure of liganded MR in which the $\zeta$ - and $\varepsilon^{2}$-nitrogens of Lys 166 and His 297 are positioned equidistant from the $\alpha$-carbon of the ligand (i.e., 3.3 and 3.4 $\AA$, respectively). The general acid/base catalysts are also in nearly equal proximity to the nitrogen atom attached to the phenyl ring of $\mathrm{CfN}$, with distances of 3.2 and $3.4 \AA$ to the $\zeta$ - and $\varepsilon^{2}$-nitrogens of Lys 166 and His 297, respectively (data not shown). The equal distance of the general acid/base catalytic residues from the $\alpha$-carbon equivalent of the intermediate analogues suggests that these structures provide a genuine snapshot of the conformation of MR attained upon binding the acicarboxylate intermediate during catalysis. Alternatively, the position of the Lys 166 side chain observed in these structures may represent the bona fide position of the $S$-specific general base throughout catalysis. In previous structures of MR complexed with (S)-atrolactate,(42-44)steric interactions between the Lys 166 side chain and the $\alpha$-methyl group of $(S)$-atrolactate may have pushed the side chain of Lys 166 farther from the substrate than may truly be the case when the $(S)$-mandelate substrate is bound.

\section{Figure 4}



Figure 4. Representative simulated annealing omit maps for $\mathrm{Mg}^{2+}-\mathrm{BzH}(\mathrm{A})$ and $\mathrm{Mg}^{2+}-\mathrm{CfN}(\mathrm{B})$ complexes in the active site of MR. The electron density maps are contoured at $3.0 \sigma$ and extend to a distance of $7 \AA$ from the ligand. 




Figure 5. Side chain movements associated with intermediate analogue binding. (A) Structural overlay of the MR-BzH complex with the MR-(S)-atrolactate complex (PDB entry 1 MDR). The catalytic amino acid side chain positions are colored gray for the structure in the presence of $(S)$-atrolactate and blue for the structure in the presence of $\mathrm{BzH}$. The $S$-specific general base catalyst, Lys 166 , is repositioned in the presence of the planar intermediate analogue such that the $\zeta$-nitrogen is $3.3 \AA$ from the $\alpha$-carbon of $\mathrm{BzH}$. This distance is equal to that of the $R$-specific general base catalyst, $\mathrm{His} 297$, from the $\alpha$-carbon of $\mathrm{BzH}$. (B) Structural overlay of the $\mathrm{MR}-\mathrm{Bz} \mathrm{H}$ complex (green), the MR-CfN complex (orange), and the MR-(S)-atrolactate complex (PDB entry 1MDR, gray). Both Tyr 54 and Phe 52 move closer to the intermediate analogues, providing structural evidence of a more constrained hydrophobic cavity in the intermediate-bound state. The 20s and 50s loops are colored yellow and pink, respectively. These loops do not exhibit any significant motion accompanying the binding of the planar intermediate analogues. (C) Stereoview illustrating the variation in active site cavities in the $1 \mathrm{MDR}$ (white), BzH (pink), and CfN (green) dimers. The decrease in the cavity volume of the intermediate analogue structures comes from movement of the Lys 166 side chain along with a slight inward movement of the backbone chain connecting the end of this $\beta$-strand to the subsequent $\alpha$-helix, and from a general constriction of the hydrophobic cavity. Cavity volumes were calculated with a water probe at the van der Waals radius of $1.4 \AA$ using VOIDOO.(47) All calculations were performed on a single active site with the ligand and $\mathrm{Mg}^{2+}$ removed and the contribution to the active site from the dimerization interface included. In all cases, the cavity search was initiated at the equivalent of the $\beta$-carbon position of $(S)$-atrolactate in chain $A$, after all PDB files had been structurally overlaid for chain A. The calculated protein surface lining the 1 MDR cavity (over a $14 \AA \times 14 \AA \times 12 \AA$ grid map) is displayed as a partially translucent white isosurface. The yellow mesh illustrates the active site cavity in $1 \mathrm{MDR}$, the green mesh that in the MR-CfN complex, and the pink mesh that in the MR-BzH complex. (S)-Atrolactate is illustrated as yellow sticks. All residues lining the cavity are shown and labeled. Leu 93' from the neighboring chain can be seen behind $(S)$-atrolactate and, for the sake of clarity, is not labeled.

Hydrophobic effects contribute to TS stabilization by MR,(46) suggesting a possible role for hydrophobic cavity residues in specifically stabilizing the altered substrate in the TS. However, no major changes in the positions of hydrophobic amino acid side chains located in the hydrophobic cavity can be confidently identified 
in the structures of MR with either bound $\mathrm{CfN}$ or $\mathrm{BzH}$ at 2.2- $\AA$ resolution. That said, Tyr 54, which is part of the 50 s loop of the $S$-specific pocket,(19) does appear to change its orientation slightly in the intermediate-bound state, moving closer to the phenyl ring of $\mathrm{BzH}$ and $\mathrm{CfN}$, thereby raising the possibility that it may interact with the phenyl ring of the aci-carboxylate intermediate during catalysis (Figure $\underline{5} \mathrm{~B})$. To assess whether Tyr 54 plays a specific role in TS stabilization by MR, the Y54F and Y54L mutants were generated and the impact of these mutations on the interconversion of $(R)$ - and $(S)$-mandelate was determined. Relative to those of wild-type MR, the $\mathrm{Y} 54 \mathrm{~F}$ mutation had negligible effects on the values of $K_{\mathrm{m}}, k_{\mathrm{cat}}$, and $k_{\mathrm{cat}} / K_{\mathrm{m}}$ when either $(R)$ - or $(S)$-mandelate was the substrate, and the binding affinity of $\mathrm{BzH}$ was not altered significantly for this mutant (Table 2 ). Hence, interactions with the hydroxyl group of Tyr 54 do not play a significant role in TS stabilization. If the aromatic ring of Tyr 54 plays a specific role in TS stabilization, then the Y54L mutation should exhibit a much more significant effect on $k_{\mathrm{cat}} / K_{\mathrm{m}}$ than on $K_{\mathrm{m}}$ for $(R)$ - and $(S)$-mandelate. Conversely, if Tyr 54 contributes generally to the packing of the hydrophobic cavity, the Y54L mutation is expected to have an effect on both substrate binding [manifested in $K_{\mathrm{m}}$ for $(R)$ - and $(S)$-mandelate, because $K_{\mathrm{m}}=K_{\mathrm{s}}$ for MR(3)] and TS stabilization (manifested in $k_{\text {cat }} / K_{\mathrm{m}}$ ). The Y54L mutation results in an $\sim 2$-fold increase in $K_{\mathrm{m}}$ over that of the wild-type enzyme and a 3.5fold decrease in $k_{\mathrm{cat}} / K_{\mathrm{m}}$ when either $(R)$ - or $(S)$-mandelate is the substrate (Table 2 ). Interestingly, the effect of the Y54L mutation on the steady state kinetic parameters is much smaller than the effect observed upon mutation of several other hydrophobic pocket residues (Table 2). Thus, the motion of the Tyr 54 side chain is likely a consequence of altered packing rearrangements in the hydrophobic pocket rather than a result of a specific role for Tyr 54 in TS stabilization. Nevertheless, the movement of Tyr 54 combined with a modest movement of other hydrophobic cavity side chains such as Phe 52 (Figure $\underline{5} \mathrm{~B}$ ) suggests that the entire hydrophobic cavity may contract around the planar intermediate. Indeed, estimation of the size of the hydrophobic cavity using VOIDOO (http://xray.bmc.uu.se/usf/voidoo.html)(47) indicates that the size of the hydrophobic cavity shrinks from approximately $39 \AA^{3}$ in the MR-(S)-atrolactate complex (PDB entry $\underline{1 M D R}$ ) to approximately 29 and $25 \AA^{3}$ in the MR-BzH and MR-CfN complexes, respectively (Figure $\underline{5} \mathrm{C}$ ). Much of this reduction in cavity volume results from the movement of Lys 166 , but there is also a notable reduction in the cavity volume of the hydrophobic pocket. These observations are in accord with the observed contribution of hydrophobic interactions to TS stabilization.(46)

The structures of $\mathrm{MR}$ with $\mathrm{BzH}$ and $\mathrm{CfN}$ also suggest enhanced coordination of $\mathrm{Mg}^{2+}$ by the intermediate analogues relative to the ground state analogue $(S)$-atrolactate. $\mathrm{BzH}$ and $\mathrm{CfN}$ are bound in nearly equivalent positions and conformations in the enzyme active site, though the two ligands pivot slightly about the central $\alpha$ carbon, resulting in a modest deviation in the position of the aromatic ring in the hydrophobic cavity (Figure $\underline{5} B$ ). The ligand atoms responsible for chelating $\mathrm{Mg}^{2+}$ are also in nearly identical positions between the structures of MR with bound intermediate and ground state analogues (Figure $\underline{6}$ ). Superposition of the structures of MR complexed with $\mathrm{BzH}, \mathrm{CfN}$, and $(S)$-atrolactate reveals that, while the enzyme residues responsible for chelating $\mathrm{Mg}^{2+}$ do not undergo changes in their position or orientation, the distances between the chelating oxygen atoms of these compounds and the $\mathrm{Mg}^{2+}$ ion do vary. The distances between the $\mathrm{Mg}^{2+}$ and the chelating oxygen atoms of the carboxylate and hydroxyl groups of $(S)$-atrolactate are 2.2 and $2.3 \AA$, respectively, and the corresponding distances in the $\mathrm{BzH}$ and $\mathrm{CfN}$ complexes are 2.2 and $2.1 \AA$, respectively, and 2.0 and $2.1 \AA$, respectively. The decreased distances between the chelating oxygens of $\mathrm{BzH}$ and $\mathrm{CfN}$ and the $\mathrm{Mg}^{2+}$ ion suggest that the interaction with the $\mathrm{Mg}^{2+}$ ion is stronger than that in the ground state structure. Thus, some portion of the enhanced binding affinity observed for both $\mathrm{BzH}$ and $\mathrm{CfN}$ may result from their higher relative affinity for $\mathrm{Mg}^{2+}$ as compared to those of ground state ligands. $(35,48)$ Although the enhanced binding of $\mathrm{BzH}$ and $\mathrm{CfN}$, relative to that observed for the ground state analogue $(S)$-atrolactate $\left(K_{\mathrm{i}}=0.15 \mathrm{mM}(42)\right)$, may arise, in part, because $\mathrm{BzH}$ and $\mathrm{CfN}$ are better chelators of the $\mathrm{Mg}^{2+}$ ion, we do not consider $\mathrm{Mg}^{2+}$ chelation to be a feature that is independent of TS mimicry. Enhanced interaction with the divalent metal ion is an expected feature of the aci-carboxylate intermediate, which bears an additional negative charge relative to $(R)$ - or $(S)$-mandelate, or (S)-atrolactate. If the high affinity of $\mathrm{BzH}$ was primarily a result of $\mathrm{Mg}^{2+}$ chelation properties of the hydroxamate functional group, one would expect $\mathrm{MR}$ to bind acetohydroxamate $\left(K_{\mathrm{i}}=27 \mathrm{mM}\right)$ with an affinity greater than what is observed(46) because the stability constants for complexes of $\mathrm{BzH}$ and acetohydroxamate with $\mathrm{Mg}^{2+}$ are 
similar.(35) Consequently, other interactions with the enzyme beyond chelation effects (e.g., hydrophobic and polar interactions(46)) must also contribute to the high binding affinity of $\mathrm{BzH}$.

\section{Figure 6}



Figure 6. Structural overlay of the $\mathrm{Mg}^{2+}$-binding residues in the $\mathrm{MR}-\mathrm{BzH}$ complex (green), the MR-CfN complex (orange), and the MR-(S)-atrolactate complex (PDB entry $1 \mathrm{MDR}$, gray). The positions of all atoms coordinating the $\mathrm{Mg}^{2+}$ are nearly identical in all three structures. The $\mathrm{Mg}^{2+}$ ion is bound closer to $\mathrm{CfN}$ and $\mathrm{BzH}$ than it is to $(S)$ atrolactate, consistent with the enhanced $\mathrm{Mg}^{2+}$ binding affinity expected for these analogues. $(35,48)$

\section{Substrate Motion during Catalysis}

Analysis of site-directed mutagenesis studies(19) and competitive inhibition of MR by benzilate(46) led us to propose that the phenyl ring of mandelate traverses the hydrophobic cavity as the enzyme interconverts $(R)$ - and $(S)$-mandelate. However, the magnitude of the motion remains unknown. Two scenarios have been envisioned for this phenyl motion (Figure $\underline{7 A}$ ).(19) In one scenario, the $\beta$-carbon (C1 of the phenyl ring) remains stationary throughout the reaction, maintaining a plane with the carboxylate and hydroxyl groups. In this scenario, the $\alpha$-carbon moves by $\sim 1.0 \AA$ as it undergoes Walden inversion and the paracarbon of the phenyl ring moves by $\sim 1.8 \AA$. Alternatively, in the second scenario, the $\alpha$-carbon remains fixed throughout catalysis, resulting in a greater compensatory movement of the phenyl ring ( $\sim 2.8 \AA$ at the para carbon) as it pivots about the $\alpha$-carbon. The crystal structures of $\mathrm{MR}$ with $\mathrm{BzH}$ and $\mathrm{CfN}$ offer some insight into distinguishing between these two scenarios and suggest that the $\alpha$-carbon moves and the position of the $\beta$-carbon remains roughly fixed. Structural overlays of MR with the bound intermediate analogues compared with bound $(S)$-atrolactate (Figure $7 \mathrm{~B}$ ) reveal that (i) the $\alpha$-carbon moves $0.7-0.8 \AA$ from the position it occupies in (S)-atrolactate to the position it occupies in the planar intermediate analogues, (ii) the $\beta$-carbon remains fixed in a nearly identical position, and (iii) the para carbon of the aromatic ring moves between 0.8 and $1.2 \AA$. Consequently, the observed movement of the para carbon suggests that the total distance traversed through the hydrophobic cavity by the para carbon of the phenyl ring upon interconversion of $(S)$ - and $(R)$-mandelate is on the order of 1.6-2.4 $\AA$, reduced slightly from the value of $2.8 \AA$ (Figure $\underline{7} A$ ) by the compensating movement of the $\alpha$-carbon during catalysis. Of course, a smaller range of substrate motion in the hydrophobic pocket requires fewer rearrangements of the hydrophobic cavity during catalysis.

\section{Figure 7}




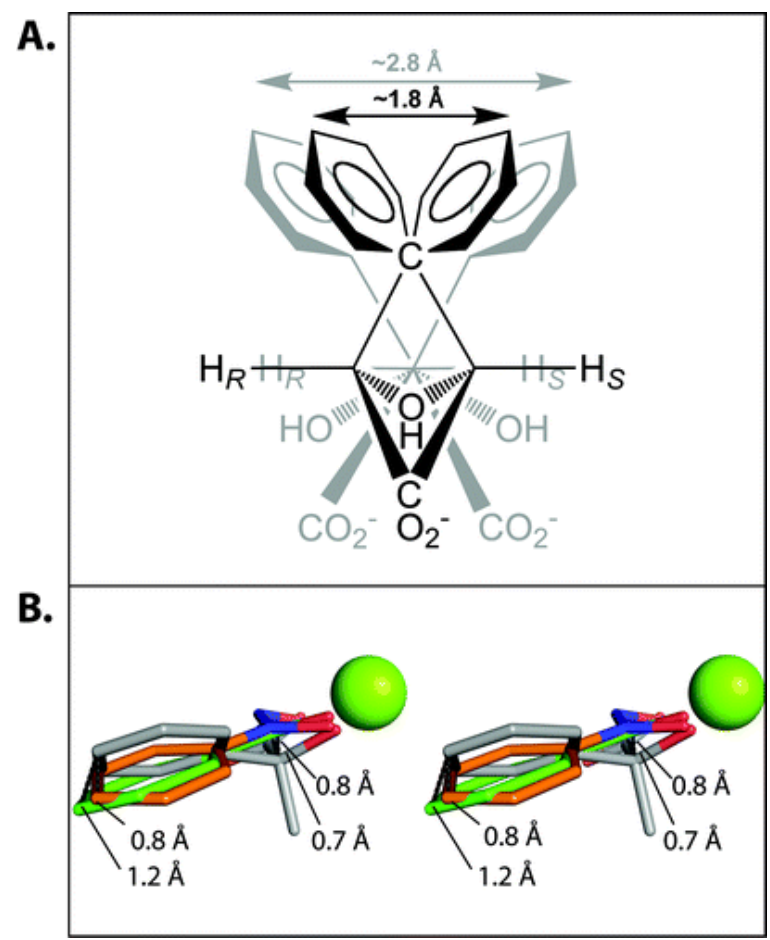

Figure 7. Motion of the phenyl group during catalysis. (A) Schematic diagram depicting two scenarios that illustrate the magnitude of motion that the phenyl ring of mandelate may undergo during catalysis.

Superimposed structures of $(R)$ - and $(S)$-mandelate are shown bound at the active site of MR. If the position of the $\alpha$-carbon remains fixed as the substrate undergoes a Walden inversion (gray structures), then the para carbon atom of the phenyl ring may traverse $\sim 2.8 \AA$ during catalysis. However, if the $\alpha$-carbon atom moves $(\sim 1.0 \AA)$ so that the hydroxyl, carboxylate, and $\beta$-carbon remain bound in the same plane as the substrate undergoes a Walden inversion (black structures), the para carbon atom of the phenyl ring may traverse $\sim 1.8 \AA$ during catalysis. (B) Stereoview of the ligands from superpositioned structures of MR complexed with (S)-atrolactate (PDB entry $\underline{1 \mathrm{MDR}}$, gray), BzH (green), and CfN (orange). From these structures,

the para carbon of the phenyl group moves $0.8-1.2 \AA$, the $\alpha$-carbon moves $0.7-0.8 \AA$, and the $\beta$-carbon remains fixed.

MR, like all members of the enolase superfamily MR subgroup, orients the substrate such that it coordinates the essential $\mathrm{Mg}^{2+}$ using one carboxylate oxygen and the $\alpha-\mathrm{OH}$ group.(49)In all enolase superfamily enzymes, the $\alpha$-carbon undergoes a transition from $\mathrm{sp}^{3}$ to $\mathrm{sp}^{2}$ hybridization as the reaction progresses from the substrate to the enolate intermediate, and the resulting structural rearrangements in the substrate have, in some instances, been proposed to play a direct role in the catalytic mechanism. For example, I-rhamnonate dehydratase, a member of the MR subgroup, has a single general acid/base residue in the active site. The transition from $\mathrm{sp}^{3}$ to $\mathrm{sp}^{2}$ hybridization of the $\alpha$-carbon in the enolate intermediate is proposed to facilitate movement of the $\beta$-carbon, permitting His 329 to function both as the general base to deprotonate the $\alpha$ carbon and as the general acid to facilitate departure of the $\beta-\mathrm{OH}$ group in the syn dehydration reaction. (50) The structures of MR with bound intermediate analogues suggest that, for members of the MR subgroup, which orient the substrate to coordinate $\mathrm{Mg}^{2+}$ with the $\alpha-\mathrm{OH}$ group, the $\beta$-carbon is not likely to undergo significant movement as the reaction proceeds from the ground state to the intermediate state. Rather, the general acid/base catalyst itself may move closer to the intermediate. Just such a movement is observed for Lys 166 in $M R$ when the structure of MR with bound $(S)$-atrolactate is compared with the structures of MR with bound intermediate analogues (Figure $\underline{5} \mathrm{~A}$ ), bearing in mind the caveat outlined above concerning the steric effect of the $\alpha-\mathrm{CH}_{3}$ group of $(S)$-atrolactate. Structures of I-talarate/galactarate dehydratase, another member of the enolase superfamily MR subgroup, complexed both with a hydroxamate intermediate analogue and with the substrate also reveal greater movement of the $\alpha$-carbon than the $\beta$-carbon.(31) However, it is important to note that the introduction of a mutation into the general base, K197A, makes it difficult to directly compare the 
relative movement of these atoms in the structures because the entire ligand shifts in the direction of the void created by the K197A mutation in the I-talarate/galactarate dehydratase structure.

\section{Conclusions}

The crystal structures of MR with the bound intermediate analogues $\mathrm{BzH}$ and $\mathrm{CfN}$ reveal several structural features that had not been evident in the previously reported structures of MR with bound ground state analogues.(40-44) These are the first structures of MR bearing a ligand in which the general acid/base catalysts, Lys 166 and His 297, are located equidistant from the $\alpha$-carbon of the ligand. The distance between the chelating oxygen atoms of the intermediate analogues and the $\mathrm{Mg}^{2+}$ becomes slightly shorter, relative to the corresponding distances in the ground state structure, suggesting that both BzH and CfN form a tighter complex with the catalytic $\mathrm{Mg}^{2+}$ as would also be expected for the aci-carboxylate intermediate. Tyr 54 moves closer to the phenyl ring of the bound intermediate analogues, and there is a concomitant constriction of the hydrophobic cavity within the active site. Finally, the para carbon of the phenyl ring of the substrate pivots about the $\beta$-carbon by $0.8-1.2 \AA$ between the ground state and intermediate state, consistent with the proposal that the phenyl ring moves during MR catalysis while the polar groups remain relatively fixed. The overall protein architecture of the active site of MR with either $\mathrm{BzH}$ or CfN bound is very similar to that of MR with $(S)$ atrolactate bound, suggesting that the alterations in enzyme structure contributing to discrimination between the altered substrate in the TS and the ground state by this proficient enzyme are extremely subtle.

\section{Supporting Information}

Table S1 and Figures S1 and S2. This material is available free of charge via the Internet at http://pubs.acs.org.

- pdf

o bi2018514 si 001.pdf (446.01 kb)

\section{Structure of Mandelate Racemase with Bound Intermediate Analogues Benzohydroxamate and Cupferron}

\section{Accession Codes}

The atomic coordinates of the MR-BzH and MR-CfN complexes have been deposited in the Protein Data Bank as entries $\underline{3 U X K}$ and $\underline{3 U X L}$, respectively.

The authors declare no competing financial interest.

\section{Abbreviations}

\begin{tabular}{|l|l|}
\hline BSA & bovine serum albumin \\
\hline BzH & benzohydroxamate \\
\hline CD & circular dichroism \\
\hline CfN & Cupferron \\
\hline HEPES & 4-(2-hydroxyethyl)piperazine-1-ethanesulfonic acid \\
\hline MR & mandelate racemase \\
\hline ORF & open reading frame \\
\hline rmsd & root-mean-square deviation \\
\hline TS & transition state \\
\hline VDW & van der Waals. \\
\hline
\end{tabular}

\section{References}

1 Gerlt, J. A. (1998) Enzyme-catalyzed proton transfer reactions to and from carbon. In Bioorganic Chemistry: Peptides and Proteins (Hecht, S. M., Ed.) pp 279-311, Oxford University Press, New York. 
$\underline{2}$ Bearne, S. L. and Wolfenden, R. (1997) Mandelate racemase in pieces: Effective concentrations of enzyme functional groups in the transition state Biochemistry 36, 1646- 1656

$\underline{3}$ St. Maurice, M. and Bearne, S. L. (2002) Kinetics and thermodynamics of mandelate racemase catalysis. Biochemistry 41, 4048- 4058

4 Babbitt, P. C. and Gerlt, J. A. (1997) Understanding enzyme superfamilies. Chemistry as the fundamental determinant in the evolution of new catalytic activities J. Biol. Chem. 272, 30591- 30594

$\underline{5}$ Babbitt, P. C., Hasson, M. S., Wedekind, J. E., Palmer, D. R., Barrett, W. C., Reed, G. H., Rayment, I., Ringe, D.,Kenyon, G. L., and Gerlt, J. A. (1996) The enolase superfamily: A general strategy for enzymecatalyzed abstraction of the $\alpha$-protons of carboxylic acids Biochemistry 35, 16489- 16501

6 Gerlt, J. A. and Gassman, P. G. (1993) Understanding the rates of certain enzyme-catalyzed reactions: Proton abstraction from carbon acids, acyl-transfer reactions, and displacement reactions of phosphodiesters. Biochemistry 32, 11943- 11952

$\underline{7}$ Gerlt, J. A., Kenyon, G. L., Kozarich, J. W., Neidhart, D. C., and Petsko, G. A. (1992) Mandelate racemase and class-related enzymes Curr. Opin. Struct. Biol. 2, 736- 742

$\underline{8}$ Radzicka, A. and Wolfenden, R. (1995) Transition state and multisubstrate analog inhibitors Methods Enzymol.249, 284- 312

9 Schramm, V. L. (2003) Enzymatic transition state poise and transition state analogues Acc. Chem. Res. 36,588- 596

10 Schramm, V. L. (2007) Enzymatic transition state theory and transition state analogue design J. Biol. Chem.282, 28297-28300

11 Schramm, V. L. (1998) Enzymatic transition states and transition state analog design Annu. Rev. Biochem.67, 693- 720

12 Wolfenden, R. and Frick, L. (1987) Transition state affinity and the design of enzyme inhibitors. In Enzyme Mechanisms (Page, M. I. and Williams, A., Eds.) pp 97-122, Royal Society of Chemistry, London.

13 Bourque, J. R., Burley, R. K., and Bearne, S. L. (2007) Intermediate analogue inhibitors of mandelate racemase: $\mathrm{N}$-Hydroxyformanilide and Cupferron Bioorg. Med. Chem. Lett. 17, 105- 108

14 Burley, R. K. and Bearne, S. L. (2005) Inhibition of mandelate racemase by the substrate-intermediate-product analogue 1,1-diphenyl-1-hydroxymethylphosphonate Bioorg. Med. Chem. Lett. 15, 4342- 4344

15 St. Maurice, M. and Bearne, S. L. (2000) Reaction intermediate analogues for mandelate racemase: Interaction between Asn 197 and the $\alpha$-hydroxyl of the substrate promotes catalysis Biochemistry 39, 13324-13335

16 St. Maurice, M., Bearne, S. L., Lu, W., and Taylor, S. D. (2003) Inhibition of mandelate racemase by $\alpha-$ fluorobenzylphosphonates Bioorg. Med. Chem. Lett. 13, 2041- 2044

17 Narmandakh, A. and Bearne, S. L. (2010) Purification of recombinant mandelate racemase: Improved catalytic activity Protein Expression Purif. 69, 39-46

18 St. Maurice, M. (2003) The role of binding determinants in ground state and transition state stabilization by mandelate racemase. Ph.D. Thesis, p 244, Dalhousie University, Halifax, NS.

19 Siddiqi, F., Bourque, J. R., Jiang, H., Gardner, M., St. Maurice, M., Blouin, C., and Bearne, S.

L. (2005) Perturbing the hydrophobic pocket of mandelate racemase to probe phenyl motion during catalysis Biochemistry 44, 9013-9021

20 Bourque, J. R. and Bearne, S. L. (2008) Mutational analysis of the active site flap (20s loop) of mandelate racemase Biochemistry 47, 566- 578

$\underline{21}$ Sharp, T. R., Hegeman, G. D., and Kenyon, G. L. (1979) A direct kinetic assay for mandelate racemase using circular dichroic measurements Anal. Biochem. 94, 329- 334

$\underline{22}$ Gasteiger, E., Gattiker, A., Hoogland, C., Ivanyi, I., Appel, R. D., and Bairoch, A. (2003) ExPASy: The proteomics server for in-depth protein knowledge and analysis Nucleic Acids Res. 31, 3784- 3788

23 Otwinowski, Z. and Minor, W. (1997) Processing of X-ray diffraction data collected in oscillation mode Methods Enzymol. 276, 307-326

24 McCoy, A. J., Grosse-Kunstleve, R. W., Adams, P. D., Winn, M. D., Storoni, L. C., and Read, R. J. (2007) Phaser crystallographic software J. Appl. Crystallogr. 40, 658-674 
$\underline{25}$ Emsley, P., Lohkamp, B., Scott, W. G., and Cowtan, K. (2010) Features and development of Coot Acta Crystallogr. D66, 486- 501

$\underline{26}$ Vagin, A. A., Steiner, R. S., Lebedev, A. A., Potterton, L., McNicholas, S., Long, F., and Murshudov, G. N. (2004)REFMAC5 dictionary: Organisation of prior chemical knowledge and guidelines for its use Acta Crystallogr. D60,2284- 2295

27 Moriarty, N. W., Grosse-Kunstleve, R. W., and Adams, P. D. (2009) Electronic ligand builder and optimization Workbench (eLBOW): A tool for ligand coordinate and restraint generation Acta Crystallogr. D65, 10741080

28 Gulick, A. M., Hubbard, B. K., Gerlt, J. A., and Rayment, I. (2000) Evolution of enzymatic activities in the enolase superfamily: Crystallographic and mutagenesis studies of the reaction catalyzed by d-glucarate dehydratase from Escherichia coli Biochemistry 39, 4590- 4602

29 Poyner, R. R. and Reed, G. H. (1992) Structure of the bis divalent cation complex with phosphonoacetohydroxamate at the active site of enolase Biochemistry 31, 7166-7173

30 Wedekind, J. E., Poyner, R. R., Reed, G. H., and Rayment, I. (1994) Chelation of serine 39 to $\mathrm{Mg}^{2+}$ latches a gate at the active site of enolase: Structure of the bis $\left(\mathrm{Mg}^{2+}\right)$ complex of yeast enolase and the intermediate analog phosphonoacetohydroxamate at 2.1-Å resolution Biochemistry 33, 9333-9342

$\underline{31}$ Yew, W. S., Fedorov, A. A., Fedorov, E. V., Almo, S. C., and Gerlt, J. A. (2007) Evolution of enzymatic activities in the enolase superfamily: I-Talarate/galactarate dehydratase from Salmonella typhimurium LT2 Biochemistry 46,9564- 9577

32 Bartlett, P. A. and Marlowe, C. K. (1983) Phosphonamidates as transition-state analogue inhibitors of thermolysin Biochemistry 22, 4618-4624

33 Phillips, M. A., Kaplan, A. P., Rutter, W. J., and Bartlett, P. A. (1992) Transition-state characterization: A new approach combining inhibitor analogues and variation in enzyme structure Biochemistry 31, 959- 963

34 Exner, O., Hradil, M., and Mollin, J. (1993) Dissociation of hydroxamic acids: Solvent effects Collect. Czech. Chem. Commun. 58, 1109- 1121

35 Farkas, E., Enyedy, E. A., and Csoka, H. (2000) Some factors affecting metal ion-monohydroxamate interactions in aqueous solution J. Inorg. Biochem. 79, 205- 211

36 Pyatnitokii, I. V. (1946) Dissociation constant of nitrosophenylhydroxylamine Zh. Anal. Khim. 1, 135-139

37 Lobanov, F. I., Savostina, V. M., and Peshkova, V. M. (1969) Complexing of titanium(IV) with Cupferron in an acid medium Khimiya 24, 95- 97

38 Martell, A. E. and Smith, R. M. (1977) Critical Stability Constants, Vol. 3, Plenum Press, New York.

39 Gerlt, J. A. and Gassman, P. G. (1993) An explanation for rapid enzyme-catalyzed proton abstraction from carbon acids: Importance of late transition states in concerted mechanisms J. Am. Chem. Soc. 115, 11552-11568

40 Neidhart, D. J., Howell, P. L., Petsko, G. A., Powers, V. M., Li, R. S., Kenyon, G. L., and Gerlt, J. A. (1991)Mechanism of the reaction catalyzed by mandelate racemase. 2. Crystal structure of mandelate racemase at $2.5-\AA \AA$ resolution: Identification of the active site and possible catalytic residues Biochemistry 30, 9264-9273

$\underline{41}$ Kallarakal, A. T., Mitra, B., Kozarich, J. W., Gerlt, J. A., Clifton, J. G., Petsko, G. A., and Kenyon, G. L. (1995)Mechanism of the reaction catalyzed by mandelate racemase: Structure and mechanistic properties of the K166R mutant Biochemistry 34, 2788- 2797

$\underline{42}$ Landro, J. A., Gerlt, J. A., Kozarich, J. W., Koo, C. W., Shah, V. J., Kenyon, G. L., Neidhart, D. J., Fujita, S., andPetsko, G. A. (1994) The role of lysine 166 in the mechanism of mandelate racemase from Pseudomonas putida: Mechanistic and crystallographic evidence for stereospecific alkylation by (R)- $\alpha$-phenylglycidate Biochemistry 33,635-643

$\underline{43}$ Schafer, S. L., Barrett, W. C., Kallarakal, A. T., Mitra, B., Kozarich, J. W., Gerlt, J. A., Clifton, J. G., Petsko, G. A., and Kenyon, G. L. (1996) Mechanism of the reaction catalyzed by mandelate racemase: Structure and mechanistic properties of the D270N mutant Biochemistry 35, 5662- 5669 
44 Mitra, B., Gerlt, J. A., Babbitt, P. C., Koo, C. W., Kenyon, G. L., Joseph, D., and Petsko, G. A. (1993) A novel structural basis for membrane association of a protein: Construction of a chimeric soluble mutant of $(S)$ mandelate dehydrogenase from Pseudomonas putida Biochemistry 32, 12959- 12967

45 Whitman, C. P., Hegeman, G. D., Cleland, W. W., and Kenyon, G. L. (1985) Symmetry and asymmetry in mandelate racemase catalysis Biochemistry 24, 3936- 3942

46 St. Maurice, M. and Bearne, S. L. (2004) Hydrophobic nature of the active site of mandelate racemase Biochemistry 43, 2524-2532

47 Kleywegt, G. J., Zou, J. Y., Kjeldgaard, M., and Jones, T. A. (2001) Around O. In International Tables for Crystallography, Volume F. Crystallography of Biological Macromolecules (Rossmann, M. G. and Arnold, E., Eds.) pp 353-356, 366-367, Kluwer Academic Publishers, Dordrecht, The Netherlands.

$48 \mathrm{Kim}$, S.-J., Yoon, C.-J., and Chang, I.-S. (1969) Studies on metal cupferrate complexes in mixed solventsTaehan Hwahakhoe Chi 13, 16- 24

$\underline{49}$ Gerlt, J. A., Babbitt, P. C., and Rayment, I. (2005) Divergent evolution in the enolase superfamily: The interplay of mechanism and specificity Arch. Biochem. Biophys. 433, 59-70

$\underline{50}$ Rakus, J. F., Fedorov, A. A., Fedorov, E. V., Glasner, M. E., Hubbard, B. K., Delli, J. D., Babbitt, P. C., Almo, S. C., and Gerlt, J. A. (2008) Evolution of enzymatic activities in the enolase superfamily: I-Rhamnonate dehydratase Biochemistry 47, 9944-9954

$\underline{51}$ Taylor, D. K., Bytheway, I., Barton, D. H. R., Bayse, C. A., and Hall, M. B. (1995) Toward the generation of NO in biological systems. Theoretical studies of the $\mathrm{N}_{2} \mathrm{O}_{2}$ grouping J. Org. Chem. 60, 435- 444

$\underline{52}$ Sjoberg, P. and Politzer, P. (1990) Use of the electrostatic potential at the molecular surface to interpret and predict nucleophilic processes J. Phys. Chem. 94, 3959- 3961 